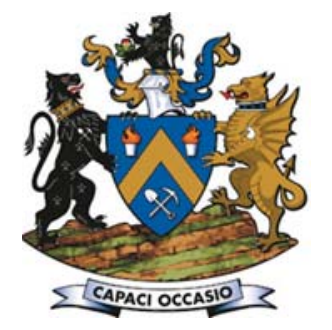

\title{
An investigation of failure modes and failure criteria of rock in complex stress states
}

\author{
by Z. Li*, J. Shi*, and A. Tang*
}

\section{Synopsis}

Rock in engineering and geological environments is usually in complex stress states. Based on many experimental results for rock under different loading conditions, and combined with failure modes found in previous studies, stress triaxiality is introduced to describe different stress states, and the relationship between failure modes and stress triaxiality is analysed in detail. For a given kind of rock, with decreasing stress triaxiality the failure mechanism changes from tension fracture to local shear failure and general shear failure. Two demarcation points of stress triaxiality exist: between tension fracture and local shear failure, and between local shear failure and general shear failure. The controlling parameters that dominate tension fracture, local shear failure, and general shear failure are different. Using a reasonable assumption based on the experimental results, a failure criterion corresponding to three distinct failure modes is presented. This failure criterion is defined by seven material parameters. The accuracy and applicability of the proposed failure criterion are examined using experimental data derived for sandstone in this study and published experimental data for rock salt and marble under conventional triaxial compression tests. The data used covers a wide range of stress triaxiality and various failure mechanisms. The predictions from the proposed failure criterion agree well with the experimental data.

\section{Keywords}

rock mechanics, tension fracture, shear failure, stress triaxiality, failure criterion.

\section{Introduction}

Determination of rock mass strength is important in most rock engineering analyses that are based on solid mechanics. Better understanding of rock mass strength will facilitate proper engineering design of structures. The loading condition of rock is complex, and a rock failure criterion represents the strength of rock under different loading conditions. Many failure criteria have been proposed by researchers during the past decades. In rock engineering practice, the linear Mohr-Coulomb (MC) criterion and the nonlinear Hoek-Brown (HB) criterion are widely used in conditions where $\sigma_{2}=\sigma_{3}$, largely due to their simplicity in formulation and the large amount of experimental data available (Melkoumian, Priest, and Hunt, 2009), despite the fact that the physical sense of the former is obscure and the latter is of a purely empirical character. Both the abovementioned criteria suffer limitations

* School of Civil Engineering and Architecture, Xi'an University of Technology, Xi'an, China.

(C) The Southern African Institute of Mining and Metallurgy, 2017. ISSN 2225-6253. Paper received Jun. 2015; revised paper received Dec. 2015.

arising from ignoring the effect of the intermediate principal stress $\left(\sigma_{2}\right)$ on rock strength (Chang and Haimson, 2012; Haimson, 2006; Tiwari and Rao, 2004). Much of the experimental evidence accumulated so far strongly suggests that $\sigma_{2}$ has a considerable effect on rock strength (Chang and Haimson, 2012; Tanapol, Chaowarin, and Kittitep, 2013; Tarasov and Potvin, 2013). To incorporate the influence of $\sigma_{2}$, several general failure criteria have been proposed, among which the Drucker-Prager criterion, the modified Lade criterion, the 3D Hoek-Brown criterion, and the unified strength criterion are well-known (Xie and Chen, 2004). However, these failure criteria are not commonly employed in practice. According to several comparative studies, none of the existing 3D failure criteria has a significant advantage over others, from both mathematical and practical points of view.

A perceived shortcoming of the traditional failure criteria is that they are established only on the basis of macroscopic experiments and combined theoretical analysis, and they do not attempt to microscopically analyse the failure mechanism and failure criterion of rock under different loading conditions. In fact, the study of deformation and failure of rock on the micro-meso scale can reveal the innate character and relationship between the macroscopic response, in the form of deformation or failure, and the intrinsic microscopic mechanism (Adelinet et al., 2013; Lin et al., 2015; Zhou and Linn, 2013; Zhou and Linn, 2014). 


\section{An investigation of failure modes and failure criteria of rock in complex stress states}

Over the past few decades, many researchers have devoted considerable effort to the study of failure and deformation of rock under different loading conditions from both the microscopic and mesoscopic points of view (Arora and Mishra, 2015; Cai and Liu, 2009; Kittitep and Decho, 2012; Loaiza et al., 2012; Tang and Hudson, 2010; Wong and Baud, 2012; Xie et al., 2012; Yang et al., 2008; Yang, Jing, and Wang., 2012; Zhong, Liu, and Ma., 2015). When the confining pressure is zero or very low, macroscopic failure is typically associated with axial splitting. As the confining pressure is increased, the failure process changes to a macroscopic shear failure. Loaiza (2012) also observed two deformation modes of basaltic rock under triaxial loading. At low confining pressure, shear localization occurs. At high confining pressure, shear-enhanced compaction appears. Amann, Kaiser, and Button (2012) suggested that brittle failure processes tend to be suppressed when the confining pressure is increased beyond a threshold. Xie (2004) outlined the failure modes of rock under several common loading conditions including splitting under uniaxial compression, shear failure under conventional triaxial compression with medium confining pressure, and plastic failure under conventional triaxial compression with high confining pressure. Several laboratory studies on artificial materials with inclined pre-existing flaws under uniaxial and biaxial compressive loading conditions have been utilized to investigate the influence of $\sigma_{3}$ on fracture propagation and the resulting failure mode. The results suggest that confinement suppresses the growth of propagating tensile microcracks (Salvador, Rafael, and Alexandra, 2013; Yang, Jing, and Wang, 2012). Szwedzicki (2007) asserted that the variations in uniaxial compressive strength values of samples from the same lithology depend on the failure mode. Within the same failure mode, the variations may be relatively small. When various failure modes take place in similar samples, variations can often be very large. This means that the failure mode affects the resultant strength of the sample. These experimental studies collectively show that the stress state has a strong influence on the failure processes and the resulting failure mode, and the way in which the sample fails affects the obtained strength of rock samples. This should be considered in the development of a failure criterion. The strength value is a function of the failure mode. An ideal failure criterion should be able to predict not only the stress state at failure but also the failure mode. The dominant factors for different failure modes also vary, so it is difficult to correctly predict different kinds of failure using a single failure criterion. However, the relationship between the failure mode and strength parameters has not been investigated, and a failure criterion that can incorporate the effect of different failure modes is rarely applied. The effect of the stress state on the rock failure and deformability has also been inadequately investigated.

It has been pointed out that a common deficiency in assessment of the rock strength is that it does not take into account the failure mode of rock. This could explain the large range of experimental results obtained on rock samples. In the present study, an attempt will be made to establish a new failure criterion based on three different failure modes proposed in previous research. Here, the stress triaxiality is selected to measure different failure modes for a given type of rock. The factors that influence the occurrence of different failure modes are investigated and the parameters that control failure are determined. Therefore, this failure criterion is widely applicable to different failure modes. Furthermore, it can predict not only the stress state at failure but also the failure mode. In the proposed criterion, seven material parameters are used. The physical meaning of these parameters and the procedures for determining them are presented. The accuracy of this proposed criterion is demonstrated by examining the experimental data on sandstone in this study and other rock types from the literature.

\section{Different failure mechanisms of rock in various stress states}

\section{Stress states in terms of stress triaxiality}

Let $\sigma_{i j}$ be the stress tensor and $\sigma_{1}, \sigma_{2}$, and $\sigma_{3}$ the principal stresses, and assume that $\sigma_{1} \geq \sigma_{2} \geq \sigma_{3}$. The mean stress and the equivalent (Von Mises) stress can be expressed as

$$
\begin{aligned}
& \sigma_{\mathrm{m}}=\left(\sigma_{1}+\sigma_{2}+\sigma_{3}\right) / 3 \\
& \sigma_{\mathrm{e}}=\sqrt{\left(\sigma_{1}-\sigma_{2}\right)^{2}+\left(\sigma_{2}-\sigma_{3}\right)^{2}+\left(\sigma_{3}-\sigma_{1}\right)^{2}} / \sqrt{2}
\end{aligned}
$$

We here consider an infinitesimal volume element subjected to a three-dimensional stress state and introduce the $\left(\sigma_{1}, \sigma_{2}, \sigma_{3}\right)$ coordinate system. The stress state $\sigma_{i j}$ can be conveniently represented as a point $P\left(\sigma_{1}, \sigma_{2}, \sigma_{3}\right)$ in the principal stress space, as shown in Figure 1a. $O N$ is a line passing through the origin and is at equal angles with the coordinate axes. This is known as the isoclinal line, and every point along this line corresponds to a hydrostatic stress state. The planes perpendicular to $O N$ are termed isoclinal planes, and the hydrostatic stress is constant on these planes. The plane perpendicular to $O N$ and passing through the origin is referred to as the $\pi$ plane and the hydrostatic stress is zero on this plane. Considering an arbitrary stress state at the point $P$ with $\sigma_{1}, \sigma_{2}$, and $\sigma_{3}$, the stress vector $O P$ can be decomposed into the components $\stackrel{+}{\alpha}$ parallel to $O N$ and $\stackrel{+}{r}$ perpendicular to $O N$. The magnitude of $\stackrel{+}{\alpha}$ and $\stackrel{+}{r}$ can be obtained by:

$$
\begin{aligned}
& a=\sqrt{3} \sigma_{\mathrm{m}} \\
& r=\sqrt{2} \sigma_{\mathrm{e}} / \sqrt{3}
\end{aligned}
$$

where $\sigma_{\mathrm{m}}$ and $\sigma_{\mathrm{e}}$ are the mean stress and the equivalent stress respectively.

To quantify the effect of the stress state on the failure mode of rocks, a dimensionless parameter called stress triaxiality is introduced to indicate the infinitesimal volume element (see Figure 1a) and to reveal stress states under different loading conditions. Stress triaxiality is represented $R_{\sigma}$ by and defined as

$$
R_{\sigma}=\sigma_{\mathrm{m}} / \sigma_{\mathrm{e}}
$$

$R_{\sigma}$ is given by: 


\section{An investigation of failure modes and failure criteria of rock in complex stress states}

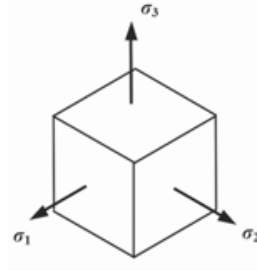

(a)

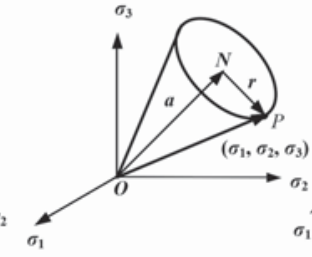

(b)

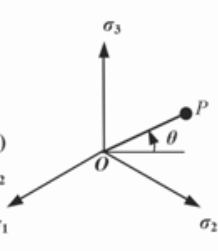

(c)
Figure 1-(a) Stress state of an infinitesimal volume element, (b) stress states with the same stress triaxiality ratio, (c) projection of a stress state on the $\pi$-plane

$$
R_{\sigma}=\sqrt{2} a /(3 r)
$$

It is obvious that, for a given stress triaxiality ratio $R_{\sigma}$, we have an infinite number of stress states, each of which corresponds to a point on the conical surface with the axis ON (Figure 1b). For a stress state with specific stress components, $\sigma_{1}, \sigma_{2}$, and $\sigma_{3}, R_{\sigma}$ can be determined uniquely, with its value reflecting the ratio of the volumetric strain to the elastic shear strain.

The calculation results for stress triaxiality in several different stress states are given in Table I. It should be noted that the principal stresses in the stress states of triaxial tension and conventional triaxial compression in Table I are assumed.

As shown in Table I, with the stress states changing progressively from triaxial tension to uniaxial tension, uniaxial compression, and triaxial compression, the value of stress triaxiality decreases constantly. If the value of stress triaxiality is positive, the stress state is tension and the larger the value of stress triaxiality, the stronger the degree of tension. If the value of stress triaxiality is negative, the stress state is compression and the smaller the value, the stronger the degree of compression. It has been widely postulated that the failure mechanism depends upon the stress state for a given type of rock. The one-to-one relationship between each stress state and the value of its stress triaxiality is obvious

Table I

\section{The values of stress triaxiality in different stress states}

\begin{tabular}{|l|c|c|c|c|}
\hline \multirow{2}{*}{ Stress state } & \multicolumn{3}{|c|}{ Principal stress } & \multirow{2}{*}{$\boldsymbol{R}_{\sigma}$} \\
\cline { 2 - 4 } & $\sigma_{1}$ & $\sigma_{2}$ & $\sigma_{3}$ & \\
\hline Triaxial inequivalent tension & $\sigma$ & $\sigma$ & $0.5 \sigma$ & 1.67 \\
Biaxial equivalent tension & $\sigma$ & $\sigma$ & 0 & 0.67 \\
Uniaxial tension & $\sigma$ & 0 & 0 & 0.33 \\
Pure shear & $\sigma$ & 0 & $-\sigma$ & 0 \\
Uniaxial compression & 0 & 0 & $-\sigma$ & -0.33 \\
Conventional triaxial compression & $-0.2 \sigma$ & $-0.2 \sigma$ & $-\sigma$ & -0.58 \\
Conventional triaxial compression & $-0.4 \sigma$ & $-0.4 \sigma$ & $-\sigma$ & -1.00 \\
Conventional triaxial compression & $-0.6 \sigma$ & $-0.6 \sigma$ & $-\sigma$ & -1.83 \\
Triaxial equivalent compression & $-\sigma$ & $-\sigma$ & $-\sigma$ & $-\infty$ \\
& & & & \\
\hline
\end{tabular}

Notes: The values of stress triaxiality in different stress states. In Table I $R_{\sigma}$ denotes the value of stress triaxiality corresponding in different stress states, $\sigma_{1}, \sigma_{2}$, and $\sigma_{3}$ are the principal stresses, and it is assumed that $\sigma_{1}$ $\geq \sigma_{2} \geq \sigma_{3}$ according to the positive-negative prescription of stress in elastic mechanics and perfect, so it can reasonably reveal the influence of different stress factors on deformation and failure of rocks and the resulting failure mechanism. For a given type of rock, within a certain range, if the stress triaxiality is large, the volumetric deformation is relatively large due to the tensiondominated stress state, and thus the rock tends to fail by tensile fracture. If the stress triaxiality is small, the elastic shear strain is relatively large due to the compressiondominated stress state, and thus shear failure tends to take place. Under the stress state of triaxial equivalent compression with the value of stress triaxiality as $-\infty$, the shear stress is too little, and shear failure is difficult to achieve. This is mainly because, as is generally believed, that it is the tension stress that causes tension fracture and the shear stress dominates in the occurrence of shear failure, but compressive stress usually cannot lead to failure, but results in welding. Moreover, once stress triaxiality is introduced to describe the stress state, there is a uniform standard for comparing and combining the experimental results in conventional triaxial compression $\left(\sigma_{1} \geq \sigma_{2} \geq \sigma_{3}\right)$ with other loading conditions where all three principal stresses differ more in value.

In following sections we present experimental and numerical investigations to evaluate the effects of stress state on the deformation and failure of rock. These effects will be evaluated by $R_{\sigma}$.

\section{The relationship between failure modes and stress triaxiality}

Various failure mechanisms and failure modes of rocks have been put forward in many published documents (Tien, Kuo, and Juang, 2006; Wong and Baud, 2012; Xie et al., 2011). However, these different failure modes have not been classified, and different stress states have not been considered in interpreting the experimental results, nor has the relationship between failure modes and strength parameters been investigated. Laboratory testing proved that many factors, including loading condition, confining pressure, and extent of microscopic discontinuities, could contribute to different failure modes of a rock sample.

It is known that different failure mechanisms and failure modes will manifest under various loading conditions. Under uniaxial compressive stress, due to localized stress concentrations around microscopic discontinuities, rock samples may fail in tension or in shear. In general, tension failure tends to occur in the most brittle rock, and shear failure will occur in fine-grained rock (Szwedzicki, 2007; You, 2009). Under conventional triaxial compression with higher confining pressures, shear failure tends to occur in most rock types, and this has been verified by many experiments (Tanapol, Chaowarin, and Kittitep, 2013; Tarasov and Potvin, 2013; Tiwari and Rao, 2004). Shear failure has been extensively observed in a certain stress state for a given type of rock. Which failure mode will appear in many other loading conditions - tension or shear failure? However, to our knowledge, this has not been reported yet. Therefore, we need to further clarify the complex relationship between failure mode and stress state.

In order to investigate the influence of stress state and its relationship with failure mode, conventional triaxial compression tests were conducted on sandstone and the 


\section{An investigation of failure modes and failure criteria of rock in complex stress states}

fracture surfaces of samples tested under different confining pressures were studied by scanning electron microscopy (SEM). Sandstone specimens, from Tongchuan in Shaanxi Province, China were chosen for the experimental study in this research. The sandstone has a crystalline and blocky structure, which is macroscopically very homogeneous. The main minerals in the sandstone are calcite, quartz, and feldspar, and the main chemical components are $\mathrm{Si}$ and $\mathrm{Ca}$. For this research, a total of 80 sandstone samples were prepared for carrying out conventional triaxial compression tests at confining pressures of $0,5,10,15,20,25,30,35$, $40,45,50$, and $55 \mathrm{MPa}$. The samples were drilled from two rectangular blocks. During drilling, the sandstone samples were machined along the same direction in order to avoid the influence of anisotropy on the experimental results. In order to obtain exact results as well as the best comparison, all the experiments were performed on dry specimens at room temperature. In accordance with the method suggested by the ISRM, the length-to-diameter ratio of test samples should be in the range of 2.0-3.0 in order to minimize the influence of the end friction effects on the results. Therefore, all tested sandstone samples were cylindrical with $50 \mathrm{~mm}$ diameter and $100 \mathrm{~mm}$ length. All the conventional compression tests were conducted at a loading rate of $0.002 \mathrm{~mm} / \mathrm{s}$. The failure modes of tested samples under different confining pressures are shown in Figure 2.

From Figure 2, we can see that the failure modes under different confining pressures are noticeably different. Cracks propagated parallel to the specimen's axis, and the samples failed by splitting, which represented typical brittleness with confining pressures ranging from $0 \mathrm{MPa}$ to $5 \mathrm{MPa}$, as shown in Figure $2 \mathrm{a}$ and Figure 2b. The failure mode was transformed into shear failure with increasing confining pressure. With confining pressures in the range of 10-40 $\mathrm{MPa}$, although the failure mode was shear failure on a macroscopic scale, most of these samples displayed traces of tension, illustrating that shear failure was influenced by tension and shear deformation acting together. Moreover, with increasing confining pressure the effect of tension on failure declined gradually and the angle between the fracture surface and the specimen's axis increased, as shown from
Figures $2 \mathrm{c}$ to $2 \mathrm{i}$. When the confining pressures increased to $45 \mathrm{MPa}$ and higher, the failure surfaces became flat and smooth in macroscopic view and powder-like materials were produced by severe friction near the shear fracture surfaces, indicating that failure was the result of shear stress. The fracture surfaces were about 45 degrees from the specimen's axis, as shown from Figures $2 \mathrm{j}$ to $2 \mathrm{l}$. The axial strength increased with increasing confining pressure. The test results and calculation results under different confining pressures are presented in Table II.

It can be seen from Table II that as the confining pressure increased, the value of stress triaxiality decreased and the compression degree increased, and the failure mode changed progressively from tension fracture to local shear failure and to general shear failure. Table II indicates that two samples failed by splitting at axial failure stresses of $61.8 \mathrm{MPa}$ and $77.6 \mathrm{MPa}$ respectively, and three samples failed by general shear at axial failure stresses of 263.7, 270.1, and 275 . $5 \mathrm{MPa}$. The axial failure stresses of the samples that failed by
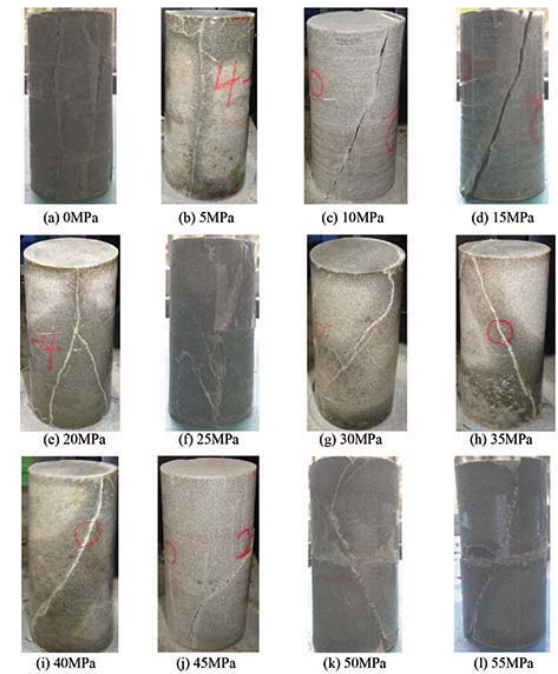

Figure 2-Failure modes of sandstone under different confining pressures. (a) $0 \mathrm{MPa}$, (b) $5 \mathrm{MPa}$, (c) $10 \mathrm{MPa}$, (d) $15 \mathrm{MPa}$, (e) $20 \mathrm{MPa}$, (f) $25 \mathrm{MPa}$, (g) $30 \mathrm{MPa}$, (h) $35 \mathrm{MPa}$, (i) $40 \mathrm{MPa}$, (j) $45 \mathrm{MPa}$, (k) $50 \mathrm{MPa}$, (l) $55 \mathrm{MPa}$

Table II

The failure parameters in conventional triaxial compression tests for sandstone

\begin{tabular}{|c|c|c|c|c|c|}
\hline Number & $\sigma_{3}(\mathrm{MPa})$ & Confining stress $=\sigma_{1}=\sigma_{2}(\mathrm{MPa})$ & $\tau_{\max }(\mathrm{MPa})$ & $R_{\sigma}$ & Failure mode \\
\hline $\begin{array}{l}1 \\
2\end{array}$ & $\begin{array}{l}-61.8 \\
-77.6\end{array}$ & $\begin{array}{l}-0.0 \\
-5.0\end{array}$ & $\begin{array}{l}30.9 \\
36.3\end{array}$ & $\begin{array}{l}-0.33 \\
-0.40\end{array}$ & Splitting \\
\hline $\begin{array}{l}3 \\
4 \\
5 \\
6 \\
7 \\
8 \\
9\end{array}$ & $\begin{array}{l}-130.3 \\
-153.4 \\
-176.3 \\
-200.3 \\
-216.1 \\
-238.3 \\
-250.6\end{array}$ & $\begin{array}{l}-10.0 \\
-15.0 \\
-20.0 \\
-25.0 \\
-30.0 \\
-35.0 \\
-40.0\end{array}$ & $\begin{array}{c}60.15 \\
69.2 \\
78.15 \\
87.65 \\
93.05 \\
101.65 \\
105.30\end{array}$ & $\begin{array}{l}-0.42 \\
-0.44 \\
-0.46 \\
-0.48 \\
-0.49 \\
-0.51 \\
-0.52\end{array}$ & Local shear \\
\hline $\begin{array}{l}10 \\
11 \\
12\end{array}$ & $\begin{array}{l}-263.7 \\
-270.1 \\
-275.5\end{array}$ & $\begin{array}{l}-45.0 \\
-50.0 \\
-55.0\end{array}$ & $\begin{array}{l}109.35 \\
110.05 \\
110.25\end{array}$ & $\begin{array}{l}-0.54 \\
-0.56 \\
-0.58\end{array}$ & General shear \\
\hline
\end{tabular}

Notes: The failure parameters in conventional triaxial compression tests for sandstone. In Table II, $\sigma_{1}, \sigma_{2}$, and $\sigma_{3}$ are the principal stresses at failure, in conventional triaxial compression tests, both $\sigma_{1}$ and $\sigma_{2}$ are the confining stresses, $\sigma_{3}$ is the axial stress at failure, $\tau_{\max }$ is the maximal shear stress at failure, and $R_{\sigma}$ denotes the values of stress triaxiality in different stress states. The unit of $\sigma_{1}, \sigma_{2}$, and $\sigma_{3}$ and $\tau_{\max }$ is $\mathrm{MPa}$, and the stress triaxiality is dimensionless 


\section{An investigation of failure modes and failure criteria of rock in complex stress states}

local shear are also presented in Table II. Therefore, the axial failure stresses of samples probably depended on their failure mode. For the same failure mode, the variations in axial failure stress may be relatively small. However, when various failure modes take place the variations may be very large.

Areas on fracture surfaces were examined by SEM under high magnification. SEM micrographs of fracture surfaces of samples that failed in various modes under various confining pressures are presented in Figure 3. It can be clearly seen that the fracture surface changed from coarse to flat and smooth with increasing confining pressure. At zero confining pressure the fracture surface was ragged and the fracture directions at different points on the fracture surface were strongly random, as shown in Figure 3a, indicating that this kind of fracture was influenced mainly by inherent flaws in the sandstone. When the confining pressure increased to 10 $\mathrm{MPa}$, although the failure mode was shear failure on a macroscopic scale (Figure 2c), the fracture at different points showed a certain level of directionality (Figure 3b), thus indicating that the shear failure was influenced by the inherent cracks and flaws. As the confining pressure increased to $30 \mathrm{MPa}$, the failure mode was also shear failure on a macroscopic scale (Figure 2g). As shown in Figure 3c, there was little random fracture initiation near the flaws and microcracks, and slip bands appeared among the original cracks, leading to an enhanced directionality of the fracture at different points. The failure mode shown in Figures $3 \mathrm{~b}$ and $3 \mathrm{c}$ was shear failure but affected by tensile stress, so it was defined as local shear failure. When the confining pressure continued to increase to $45 \mathrm{MPa}$, the failure mode was also shear failure (Figure 2j). Figure $3 \mathrm{~d}$ indicates that there was almost no random fracture initiation near the flaws and microcracks, numerous slip bands appeared among original cracks, almost all of which had the same slip direction, and the fracture at different points showed stronger directionality. At a confining pressure of $55 \mathrm{MPa}$, numerous uniformly distributed parabolic dimples appeared on the fracture surface along the same direction. The shear failure shown in Figures $3 \mathrm{~d}$ and $3 \mathrm{e}$ was controlled by shear stress and not affected by tensile stress, so it was defined as general shear failure. In this case, the samples failed in general shear failure due to the slip of shear bands, and the failure was no longer affected by voids and cracks.

Other researchers have reported similar changes of failure mode with stress states. Wang et al. (2012) found that the failure behaviour of siltstone in conventional triaxial compression tests was influenced by tension and shear deformation acting together at low confining pressures; and with increasing confining pressures, the effect of tension on failure declined to an extent that failure was completely controlled by shear deformation. That is to say, the failure mode of siltstone was local shear failure under low confining pressures; in this case, the volumetric strain had some effect on the failure, and this effect declined gradually with increasing confining pressure. Once a certain confining pressure had been reached, the failure was general shear failure and it depended entirely on the maximum shear stress. $\mathrm{Su}$ and $\mathrm{Fu}$ (2014) showed that for sandstone, splitting occurred under uniaxial compression; the maximum shear stress at failure increased with increasing confining pressure until a certain confining pressure was reached, after which the maximum shear stress at failure was almost constant. (a)

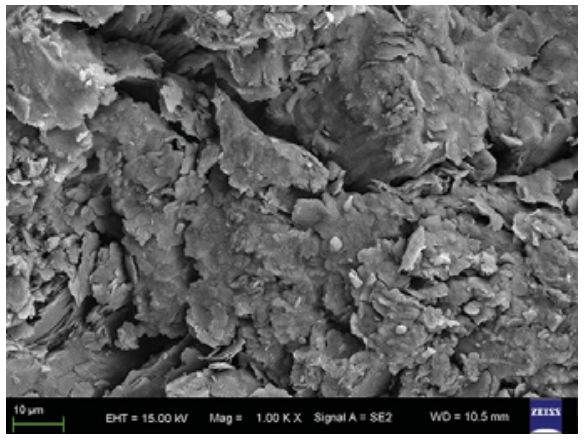

(b)

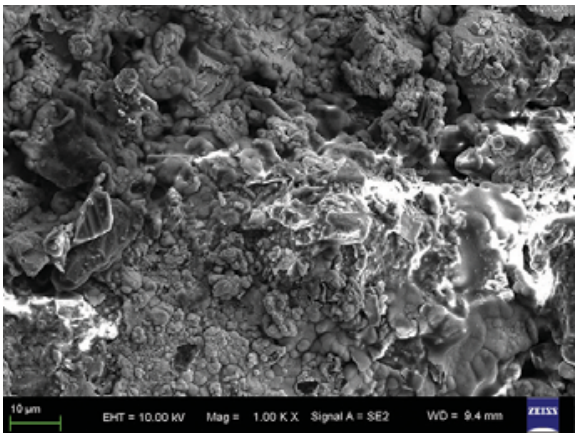

(c)

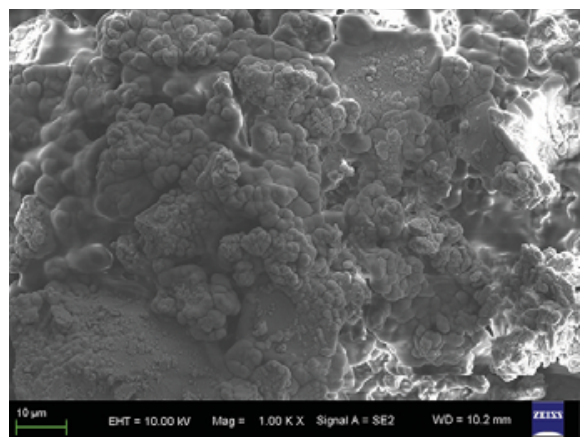

(d)
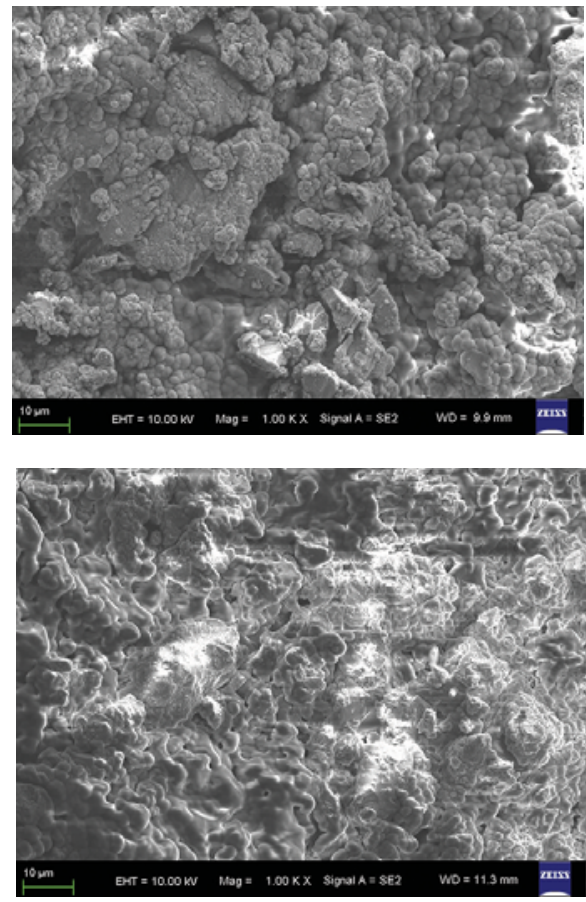

Figure 3-SEM images of fracture surfaces of sandstone under different confining pressures (x1000). (a) $0 \mathrm{MPa}$, (b) $10 \mathrm{MPa}$, (c) $30 \mathrm{MPa}$, (d) $45 \mathrm{MPa}$, (e) $55 \mathrm{MPa}$ 


\section{An investigation of failure modes and failure criteria of rock in complex stress states}

From the above test results, three distinct failure modes were identified for isotropic rock samples: tension fracture, in which tensile stress predominated; local shear failure, in which shear stress dominated; and general shear failure, in which shear stress also dominated. Both local shear failure and general shear failure fall within the scope of shear failure dominated by the shear stress. What makes them different is that the former is dominated by shear stress and influenced by tensile stress, but the latter is dominated only by shear stress, and is not influenced by tensile stress. The experimental data, including conventional compression test results for sandstone (Table II) and other published test results $(\mathrm{Su}$ and $\mathrm{Fu}, 2014$; Wang et al., 2012) provides evidence that for a given rock sample, the failure mode may change progressively from tension fracture to local shear to general shear failure as loading conditions change from unixial compression to biaxial compression and triaxial compression, and also with increasing confining pressures under conventional triaxial compression.

In this article, the stress triaxiality is applied to reveal the degree of tension and compression in different stress states. Combining the calculation results in Table I, the value of stress triaxiality decreases as the loading condition changes from axial compression to triaxial compression, and it also decreases with increasing confining pressure under conventional triaxial compression. Therefore, these observations prove that the corresponding relationship between failure modes and stress states can be as follows: for a given rock type, as the stress state changes from tension to unixial compression, biaxial compression, and triaxial compression, and also as the stress triaxiality decreases, the failure mechanism will change progressively from tension fracture to local shear failure and general shear failure. This suggests that the failure mode for a given rock sample is controlled mainly by the stress triaxiality at the weakest position. Moreover, two demarcation values of the stress triaxiality exist among these three failure mechanisms. We take $R_{1}$ and $R_{2}$ to be respectively the demarcation values of the stress triaxiality between tension fracture and local shear failure, and between local shear failure and general shear failure. Accordingly, the complete relationship between the failure mechanism and the stress triaxiality can be written as follows: the failure mechanisms at the weakest position will be tension fracture when $R_{\sigma}, \geq R_{1}$ local shear failure when $R_{2}$ $\leq R_{\sigma}<R_{1}$ and general shear failure when $R_{\sigma}<R_{2}$.

\section{The relationship between failure mode and material characteristics}

Similar to the stress state, the material characteristics also have a significant effect on the failure mechanism of rock. For different types of rock, different failure modes will occur even in the same stress state. Uniaxial compression tests of red sandstone and granite were conducted in our laboratory. Under uniaxial compression, red sandstone underwent shear failure, as shown in Figure 4a; but granite failed by longitudinal splitting, as shown in Figure 4b. Different rock properties result in varying failure modes. In the same stress state, the failure mode depends upon the degree of homogeneity; as the rock texture becomes finer and more isotropic the failure mechanism will change progressively from tension to shear failure. Coarse-grained rocks contain many flaws, and the influence of these flaws is greatest in the state of greater stress triaxiality, decreasing in the state of lower stress triaxiality. Specifically, the larger the stress triaxiality is, the higher the probability that flaws will affect the failure mode and strength.

\section{A new failure criterion corresponding to different failure modes}

The condition at failure in a rock sample can be described by the general equation

$$
f=f_{\mathrm{c}}
$$

where $f_{c}$ denotes the allowable value of $f$. When $f \geq f_{c}$, failure will occur. The definition of $f$ will be achieved in the form of tension fracture, local shear failure, and general shear failure, referred as to $f_{1}, f_{2}$, and $f_{3}$ respectively.

\section{Tension fracture}

The tension fracture observed in experiments can be classified as tension fracture under tensile stress, and splitting under uniaxial compression and triaxial compression at low confining pressures. It is easy to understand tension fracture under tensile stress. Splitting under uniaxial compression and triaxial compression at low confining pressures has been documented by various investigators (Paterson, 2005; Szwedzicki, 2007; Fakhimi and Hemami, 2015), but what causes the splitting is still obscure and there is no model for evaluating this phenomenon. In terms of failure mechanism, splitting is essentially tension fracture, but there is no tensile stress in macroscopic stress fields under loading conditions of uniaxial compression and triaxial compression at low confining pressures. Therefore, traditional failure criteria expressed by stress no longer apply.

Different rock types have unique characteristics, which also play a critical role in the whole failure process. Owing to its brittle nature, the capability of rock to withstand tensile strain is very weak. When the tensile strain at certain point reaches a critical value, the micro-crack will propagate quickly. On the other hand, due to the natural flaws and fissures inherent in rock, tension fracture is sensitive to the microstructure, and failure is obviously influenced by the local effect. For these reasons, splitting is difficult to describe in terms of the macroscopic stress field, or more
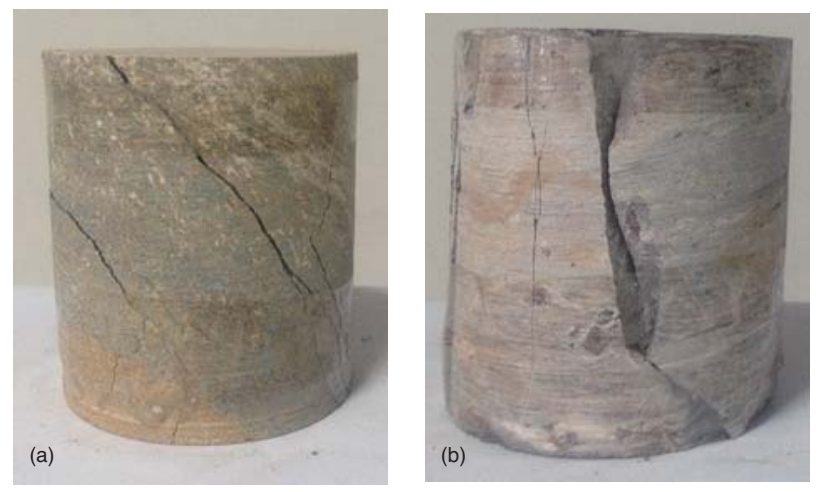

Figure 4-Different failure modes in uniaxial compression. (a) Shear failure of red sandstone, (b) longitudinal splitting of granite 


\section{An investigation of failure modes and failure criteria of rock in complex stress states}

appropriately, the strain field. The splitting observed in many experiments appeared initially along the direction of maximal tension strain, suggesting that the maximal tension strain $\varepsilon_{1}$ should be the dominant factor leading to the tension fracture. Also, the influence of other principal strains $\varepsilon_{2}$ and $\varepsilon_{3}$ on tension fracture should be included in complex stress states. Based on the above analysis, $f_{1}$ can be defined in terms of $\varepsilon_{1}$, $\varepsilon_{2}$, and $\varepsilon_{3}$ as

$$
f_{1}=\varepsilon_{1}+b_{1}\left(\varepsilon_{2}+\varepsilon_{3}\right)=f_{c 1} \text { when } R_{\sigma} \geq R_{1}
$$

Tension fracture usually occurs at the position of greatest stress concentration, and failure is dominated by the maximal tensile strain. Therefore, it is assumed that the most likely position for tension fracture is where the stress triaxiality is greatest in the stress field, and the direction of fracture initiation is consistent with the maximum tensile strain at this position. According to the newly proposed criterion for tension fracture, it is inferred that failure will occur when $f_{1}$ exceeds its maximum limit value $f_{c 1}$. Let $\varepsilon_{1}, \varepsilon_{2}$, and $\varepsilon_{3}$ represent three principal strains at the weakest position, and assume that $\varepsilon_{1} \geq \varepsilon_{2} \geq$ and $\varepsilon_{3}, b_{1}$ represents the influence coefficient of $\varepsilon_{2}$ and $\varepsilon_{3}$ on $\varepsilon_{1}$ and $f_{c 1}$ denotes the maximum limit value of $f_{1}$. Both $b_{1}$ and $f_{c 1}$ are constants that depend on the rock characteristic and can be calculated from at least two sets of experimental data in the range of tension fracture. It should be noted that Equation [8] applies only to tension fracture of rock; that is, under the condition of $R_{\sigma} \geq R_{1}$ and $\varepsilon_{1}$ $>0$ at the weakest position. A large number of experimental results (Fakhimi and Hemami, 2015; Su and Fu, 2014; Wang et al., 2012) indicate that Equation [8] can well explain and predict the splitting of rock under uniaxial compression and triaxial compression at low confining pressures.

\section{Local shear failure}

Local shear failure is dominated by the maximal shear stress and influenced by the tensile stress. We have found that the maximal shear stress at failure among samples of the same lithology varies with the stress triaxiality. Furthermore, within the same mode of local shear failure, the influence of tensile stress on local shear failure decreases progressively with decreasing stress triaxiality. The relationship between the maximal shear stress at failure and the stress triaxiality is, of course, not entirely linear. However, for convenience of application, a linear approximation is reasonable within a limited range of mean stress. Therefore $f_{2}$ can be expressed as

$$
f_{2}=\tau_{\max }+b_{2}\left(R_{\sigma}-R_{2}\right)=f_{\mathrm{c} 2} \text { when } R_{2} \leq R_{\sigma}<R_{1}
$$

where, $\tau_{\max }$ is the maximal shear stress at the weakest position, $f_{c 2}$ denotes the limit value of $f_{2}, b_{2}$ represents the influence of stress state on local shear failure, and $R_{2}$ is the demarcation value between local shear failure and general shear failure. Both $b_{2}$ and $f_{c 2}$ are constants that depend on the rock characteristics, and at least two experimental data points are required in order to determine these two parameters. They can be obtained by conducting at least two tests in different stress states within the range of local shear failure, and more testing for confirmation is highly recommended. As regards the local shear failure, because much plastic deformation in the process of failure can relax the stress concentration around the flaws and voids, the voids are difficult to grow and coalesce along the direction of the maximum tensile stress. Therefore, the shape of voids will grow into an ellipsoid or a long strip, and local shear bands will be produced among ligaments of voids. Shearlinking of voids along the direction of the maximal shear stress and the propagation of shear bands are what lead to this kind of failure. Local shear bands usually appear in the position with higher degrees of stress concentration and their propagation is dominated by the maximal shear stress. Failure is therefore modelled in terms of the maximal shear stress and the stress triaxiality, and the weakest position can also be considered as the position where the stress triaxiality is the largest in the stress field. It is important to note that Equation [9] can apply to local shear failure of rock only when $R_{2} \leq R_{\sigma}<R_{1}$.

\section{General shear failure}

General shear failure is caused by the propagation of shear bands. Unlike local shear failure, tension deformation has no influence on this kind of failure. General shear failure is not affected by tensile stress and is dominated by the maximal shear stress. Many experimental results from rock under conventional triaxial compression (Tanapol, Chaowarin, and Kittitep, 2013; Tien, Kuo, and Juang, 2006; Yang, Su, and $\mathrm{Xu}, 2005$ ) have shown that once a certain confining pressure is reached, the maximal shear stress at failure (referred to as general shear failure in this article) is almost constant. When described by the stress triaxiality, in terms of general shear failure, the maximal shear stress at failure remains almost constant with changing stress triaxiality. Based on the considerations discussed above, the failure function for predicting general shear failure is directly modelled by the maximal shear stress and can be written as

$$
f_{3}=\tau_{\max }=f_{\mathrm{c} 3} \quad \text { when } R_{\sigma}<R_{2}
$$

where $\tau_{\max }$ is the maximal shear stress at the weakest position and $f_{c 3}$, a material constant, $f_{3}$ denotes the limit value of $f_{3}$ corresponding to the onset of general shear failure. When general shear failure occurs in the specimen, the stress triaxiality is lower than in the case of local shear failure, and more plastic deformation is produced. Therefore there is almost no stress concentration around flaws in the whole failure process, shear bands are caused by the maximal shear stress, and the unstable propagation of shear bands leads to general shear failure. Shear bands tend to appear in the position with higher shape deformation energy, and their propagation is controlled by the maximum shear stress. Therefore, general shear failure is modelled only by the maximal shear stress under the assumption that the weakest position is located where the shape deformation energy is largest in the stress field, and the direction of fracture initiation is consistent with the plane of the maximum shear stress. Equation [10] can be used for general shear failure of rock only when $R_{\sigma}<R_{2}$.

In Equations [8], [9], and [10], the demarcation values of stress triaxiality $R_{1}$ and $R_{2}$ are constant for the same rock type and vary for different rock types. For a given rock type, $R_{1}$ and $R_{2}$ can be determined by a series of experiments with different failure modes in a wide range of stress triaxiality. 


\section{An investigation of failure modes and failure criteria of rock in complex stress states}

In Equations [9] and [10], $f_{c 2}$ and $f_{c 3}$ are referred as to allowable values of failure strength for local shear failure and general shear failure respectively, and they should be constant for the same rock type. As the effect of stress state on local shear failure has been included in Equation [9], $f_{c 2}$ and $f_{c 3}$ should be equal if the demarcation value of stress triaxiality between local shear failure and general shear failure is accurately determined.

\section{Experimental verification}

In order to validate the performance of the proposed failure criterion, comparisons were made between the experimental data on sandstone obtained in this investigation, the test data for rock salt and granite taken from the literature, and the predictions obtained from the proposed criterion based on Equations. [8], [9], and [10].

\section{Sandstone}

Based on the experimental data for sandstone under conventional triaxial compression tests shown in Table II the failure mode changed progressively from tension fracture to local shear failure and general shear failure with increasing confining pressure. More specifically, the failure mode was tension fracture when the confining pressure was zero and $5 \mathrm{MPa}$, local shear failure at confining pressures $n$ the range 10-40 MPa, and general shear failure at confining pressures of $45 \mathrm{MPa}$ and higher. The calculation results of the stress triaxiality in line with each confining pressure and the maximal shear stress at failure are shown in Table II. Using the test data, it can be established that the demarcation value of stress triaxiality $R_{2}$ between local shear failure and general shear failure is $R_{2}=-0.53$. Equations [9] and [10] are applied to verify the shear failure of sandstone, and the material constants $b_{2}$ and $f_{c 1}$ in Equation [9] and $f_{c 3}$ in Equation [10] are calculated by the least squares method using the third to the twelfth groups of data in Table II. The calculation results are as follows: $b_{2}=448.7 \mathrm{MPa}, f_{c 2}=$ 109.4 MPa, and $f_{c 3}=109.4 \mathrm{MPa}$. Therefore, the local shear failure criterion for sandstone results in

$$
\tau_{\max }+448.7\left(R_{\sigma}+0.53\right)=109.4\left(-0.53 \leq R_{\sigma} \leq-0.42\right)
$$

and the criterion for general shear failure is expressed as

$$
\tau_{\max }=109.4 \quad\left(R_{\sigma}<-0.53\right)
$$

In Equations. [11] and [12], the units for $\tau_{\max }$ are $\mathrm{MPa}$ and the stress triaxiality is dimensionless. The comparison between experimental data points for sandstone and criterion predictions using Equations [11] and [12] is presented in Figure 5, with stress triaxiality on the horizontal axis and maximal shear stress on the vertical one. In Figure 5, 'Max shear stress' is the maximal shear stress at the fracture position at failure under different stress states, stress triaxiality denotes the value of stress triaxiality at failure, the solid line corresponds to the predictions obtained from the proposed failure criterion through Equations [11] and [12], and the data points represent experimental results for sandstone in conventional compression tests at different confining pressures. Figure 5 gives the maximal shear stress at failure in different stress states, which is described by the stress triaxiality. As shown, to local shear failure, the maximal shear stress at failure increases approximately linearly with decreasing stress triaxiality, and to general shear failure, the maximal shear stress at failure approaches a constant with decreasing stress triaxiality, illustrating that local shear failure is influenced by the combined actions of maximal shear stress and stress triaxiality, while general shear failure is controlled only by maximal shear stress. From the comparisons shown in Figure 5, the proposed failure criterion is in perfect agreement with experimental results.

\section{Rock salt}

According to the experimental data for rock salt under conventional triaxial compression tests (Zhigalkin et al., 2008), the failure mode was always local shear at confining pressures ranging from zero to $20 \mathrm{MPa}$. The calculated results for stress triaxiality corresponding to each confining pressure and the maximal shear stress at failure are shown in Table III. Considering the lack of data on the failure mode of general shear, $R_{2}=-0.6$ is regarded as the approximate demarcation value of stress triaxiality between local shear failure and general shear failure. Material constants $b_{2}$ and

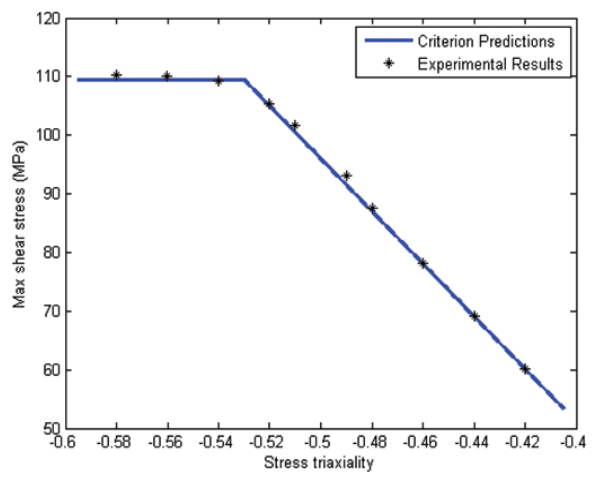

Figure 5-Comparison of experimental data and criterion predictions for sandstone. Max shear stress is the maximal shear stress at the fracture position at failure, stress triaxiality denotes the value of the stress triaxiality at failure, solid line corresponds to the predictions obtained from the proposed failure criteria given by Equations [11] and [12], data points represent experimental results for sandstone samples, the unit of Max shear stress is MPa, and the stress triaxiality is dimensionless

\section{Table III}

Failure parameters in conventional triaxial compression tests for rock salt

\begin{tabular}{|l|c|c|c|}
\hline$\sigma_{3}(\mathrm{MPa})$ & Confining stress $\sigma_{1}=\sigma_{2}$ & $\tau_{\max }(\mathrm{MPa})$ & $\boldsymbol{R}_{\boldsymbol{\sigma}}$ \\
\hline-21.4 & 0 & 10.7 & -0.33 \\
-34.7 & -1.0 & 16.9 & -0.36 \\
-45.8 & -2.5 & 21.9 & -0.39 \\
-61.2 & -5.0 & 28.1 & -0.42 \\
-67.3 & -7.5 & 29.9 & -0.46 \\
-75.8 & -10.0 & 32.9 & -0.49 \\
-109.0 & -20.0 & 44.5 & -0.56 \\
\hline
\end{tabular}

Notes: $\sigma_{1}, \sigma_{2}$, and $\sigma_{3}$ are the principal stresses at failure in conventional triaxial compression tests, $\sigma_{1}$ and $\sigma_{2}$ are the confining stresses, $\sigma_{3}$ is the axial stress at failure, $\tau_{\max }$ is the maximal shear stress at failure, and $R_{\sigma}$ denotes the values of stress triaxiality in different stress states. The unit of $\sigma_{1}, \sigma_{2}, \sigma_{3}$, and $\tau_{\max }$ is $\mathrm{MPa}$, and the stress triaxiality is dimensionless 


\section{An investigation of failure modes and failure criteria of rock in complex stress states}

$f_{c 2}$ in Equation [9] are calculated by the least squares method using all the experimental data points in Zhigalkin et al. (2008), and the calculation results are as follows: $b_{2}=$ $150 \mathrm{MPa}$, and $f_{c 2}=50.9 \mathrm{MPa}$. Therefore, the criterion for local shear failure of rock salt in Zhigalkin et al. (2008) can be expressed in terms of $\tau_{\max }$ and $R_{\sigma}$ as

$$
\tau_{\max }+150\left(R_{\sigma}+0.6\right)=50.9\left(-0.56 \leq R_{\sigma} \leq-0.33\right)
$$

In Equation [13], the units for $\tau_{\max }$ are MPa and the stress triaxiality is dimensionless. The criterion predictions using Equation [13] are compared with experimental data on rock salt from the literature in Figure 6. The solid lines correspond to the predictions obtained from the proposed failure criterion, while the data points represent experimental results. As shown in Figure 6, to local shear failure, the maximal shear stress at failure increases approximately linearly with decreasing stress triaxiality. The proposed failure criterion gives very good agreement with the experimental results.

\section{Marble}

Based on the experimental data for medium-grained marble in conventional triaxial compression tests (Yang, $\mathrm{Su}$, and $\mathrm{Xu}$, 2005), the failure mode underwent a transition from local shear to general shear with increasing confining pressure. More specifically, the failure mode was local shear at confining pressures in the range of $0-30 \mathrm{MPa}$, while general shear failure occurred when the confining pressure increased to $35 \mathrm{MPa}$ and higher. Because test data for different stress states obtained from the previous experiments is sparse, it is difficult to accurately determine the demarcation value of stress triaxiality $R_{2}$ between local shear failure and general shear failure. We can only conclude that the range of the demarcation value of stress triaxiality $R_{2}$ between local shear failure and general shear failure is $-0.5 \leq R_{2} \leq-0.48$. However, $R_{2}=-0.5$ is obtained by fitting all the test data points and the result agrees well with the data. Due to the limited data, $R_{2}=-0.5$ is estimated to be the approximate demarcation value of stress triaxiality between local shear failure and general shear failure. Material constants $b_{2}$ and

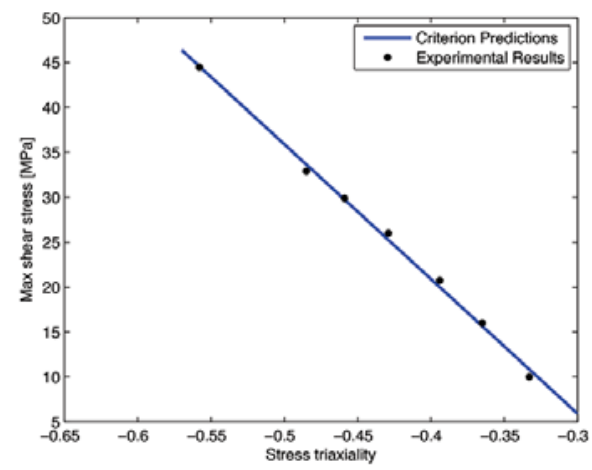

Figure 6-Comparison of experimental data (Zhigalkin et al., 2008) and criterion predictions for rock salt. Max shear stress is the maximal shear stress at the fracture position at failure, stress triaxiality denotes the value of the stress triaxiality at failure, solid line corresponds to the predictions obtained from the proposed failure criterion given by Equation [13], data points represent experimental results for salt rock, the unit of Max shear stress is MPa, and the stress triaxiality is dimensionless $f_{c 2}$ in Equation [9] and $f_{c 3}$ in Equation [10], calculated by the least squares method using all the experimental data points in Yang, $\mathrm{Su}$, and $\mathrm{Xu}$ (2005), are as follows: $b_{2}=326 \mathrm{MPa}$, $f_{c 2}=106.8 \mathrm{MPa}$, and $f_{c 3}=106.8 \mathrm{MPa}$. Therefore, the local shear failure criterion for medium-grained marble has the form

$$
\tau_{\max }+326\left(R_{\sigma}+0.5\right)=106.8\left(-0.50 \leq R_{\sigma} \leq-0.33\right)
$$

and the criterion for general shear failure is expressed as

$$
\tau_{\max }=106.8\left(R_{\sigma} \leq-0.50\right)
$$

In Equations [14] and [15], the units for $\tau_{\max }$ are $\mathrm{MPa}$. The comparison between experimental data points for medium-grained marble and criterion predictions using Equations [14] and [15] is presented in Figure 7. As shown, within the range of shear failure, the maximal shear stress at failure also approaches a constant value with decreasing stress triaxiality.

For coarse-grained marble (Yang, $\mathrm{Su}$, and $\mathrm{Xu}, 2005$ ), the failure mode was always local shear at the confining pressure between zero and $30 \mathrm{MPa}$. Due to a lack of experimental results on general shear failure, $R_{2}=-0.6$ is considered as the approximate demarcation value of stress triaxiality between local shear failure and general shear failure. Material constants $b_{2}$ and $f_{c 2}$ in Equation [9] were calculated by the least squares method using all the experimental data points in Yang, $\mathrm{Su}$, and $\mathrm{Xu}$ (2005), and the calculation results are as follows: $b_{2}=201.5 \mathrm{MPa}$, and $f_{c 2}=80 \mathrm{MPa}$. Therefore, the local shear failure criterion for coarse-grained marble (2005) can be expressed by

$$
\tau_{\max }+201.5\left(R_{\sigma}+0.6\right)=80\left(-0.54 \leq R_{\sigma} \leq-0.37\right)
$$

In Equation [16], the units for $\tau_{\max }$ are also MPa. The comparison between experimental data points for marble with coarse grains and criterion predictions using Equation [16] is given in Figure 8. As shown, to local shear failure, the maximal shear stress at failure also increases approximately linearly with decreasing stress triaxiality, which also illustrates that high stress triaxiality will speed up the occurrence of local shear failure within a certain range.

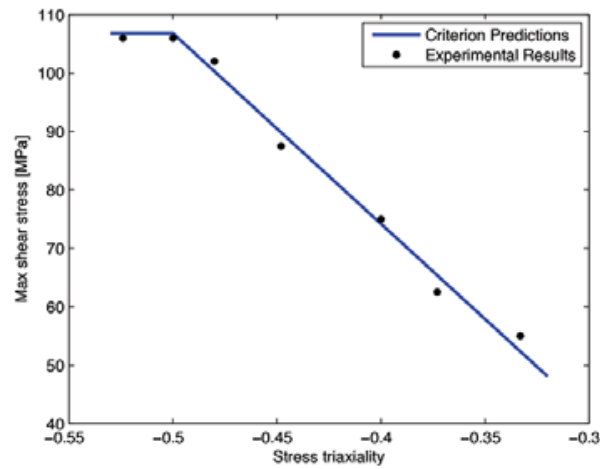

Figure 7-Comparison of experimental data (Yang, Su, and Xu, 2005) and criterion predictions for medium-grained marble. Max shear stress is the maximal shear stress at the fracture position at failure, stress triaxiality denotes the value of the stress triaxiality at failure, solid line corresponds to the predictions obtained from the proposed failure criteria given by Equations [14] and [15], data points represent experimental results for medium-grained marble, the unit of Max shear stress is $\mathrm{MPa}$, and the stress triaxiality is dimensionless 


\section{An investigation of failure modes and failure criteria of rock in complex stress states}

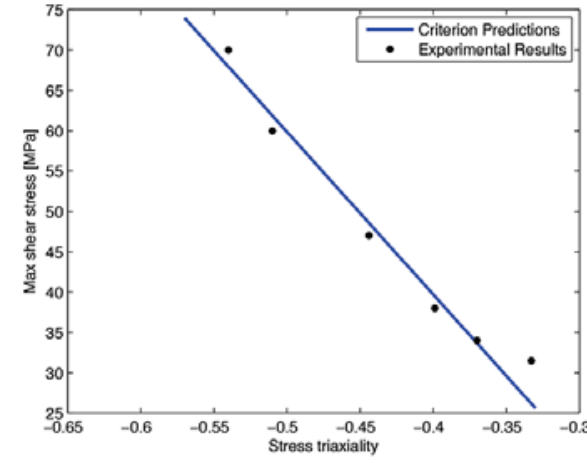

Figure 8-Comparison of experimental data (Yang, Su, and Xu, 2005) and criterion predictions for coarse-grained marble. Max shear stress is the maximal shear stress at the fracture position at failure, stress triaxiality denotes the value of the stress triaxiality at failure, solid line corresponds to the predictions obtained from the proposed failure criterion given by Equation [16], data points represent experimental results for coarse-grained marble, the unit of Max shear stress is MPa, and the stress triaxiality is dimensionless

The comparisons shown in Figures 5-8 prove that the proposed failure criterion is able to accurately predict the failure strength of isotropic rock of various types in various stress states.

As can be seen from the comparisons in Figure 7 and Figure 8, the test results for coarse-grained marble are relatively dispersive, and the experimental data for mediumgrained marble match the criterion well. Therefore the deviation between experimental data points and criterion prediction for medium-grained marble is smaller than that for coarse-grained marble. When the value of stress trialiaxity is reduced from -0.33 to -0.55 , coarse-grained marble always fails by local shear failure, but the failure mode of mediumgrained marble changes from local shear to general shear. As discussed above, material characteristics also have a significant influence on the failure mechanism and failure criteria of rock.

\section{Discussion}

From the above analyses and comparisons, it can be clearly seen that the relationship between failure mode and stress state is well described using stress triaxiality and the proposed failure criterion can accurately predict the failure of rock in different stress states. We previously investigated the fracture mechanisms of metals in various stress states $(\mathrm{Li}$, Shi, and Tang, 2014), and found that the variation law for macroscopic fracture modes with stress triaxiality for metals is similar to that for rock, but there appears a great difference between the two materials in terms of the mesoscopic mechanism. The primary factor that affects the fracture mechanism of metals is the amount of plastic deformation during the fracture process, while the major factor that influences the failure mode of rock tends to be the evolution of flaws in different stress states.

However, there are still some limitations in this method. For example, the values of stress triaxiality in the experiments were limited within a certain range. All the available data is based on conventional triaxial compression tests on rock, hence the values of stress triaxiality can only cover the range from -1 to -0.33 owing to the limited range of confining pressures generated by triaxial compression equipment. Because the values of stress triaxiality are within this range, failure modes are mainly local shear and general shear, and tension fracture appears rarely. Therefore, the experimental verification in this article is confined to the analysis of local shear failure and general shear failure. Nevertheless, the failure criterion is based on three different failure mechanisms and can be applied all failure behaviours in complex stress states.

For a given rock type, demarcation values of stress triaxiality $R_{1}$ and $R_{1}$ are constant and should be obtained by a series of experiments with different failure modes covering a wide range of stress states. Due to a lack of continuous experimental data covering a wide range of stress triaxiality, the value of $R_{2}$ in this article is estimated using the available data. For this reason, more continuous experiments over a wider range of stress triaxiality are required in order to accurately determine the demarcation values of stress triaxiality.

Moreover, the existence of microscopic discontinuities is responsible for 'size effects', that is, strength reduction with increased sample size. The larger the sample, the higher the probability that the discontinuities will affect the failure mode and the strength. Therefore, the results presented in this paper are reliable for some relatively homogeneous rock samples that can be regarded as isotropic. On the other hand, for some anisotropic and inhomogeneous rock samples, there are too many randomly distributed unknown flaws and micro-cracks in the rock, and the failure mode will be greatly influenced by these flaws and cracks, especially in states of high stress triaxiality.

\section{Conclusion}

In this article, the concept of stress triaxiality was introduced to reveal different stress states, and failure mechanisms and strengths of rock under various complex loading conditions were investigated. The major results obtained are as follows.

1. The introduction of stress triaxiality to reveal different stress states makes it possible to determine whether the rock samples fail in tension, in local shear, or in general shear. For a given rock type, with decreasing stress triaxiality, the failure mechanism will change progressively from tension fracture to local shear and general shear. Two demarcation points of stress triaxiality, expressed as $R_{1}$ and $R_{2}$, exist between tension fracture and local shear failure, and between local shear and general shear. Accordingly, the failure mode at the weakest position will be tension fracture when $R_{\sigma} \geq R_{1}$ local shear failure when $R_{2} \leq R_{\sigma}<R_{1}$ and general shear failure when $R_{\sigma<} R_{2}$.

2. Failure of rock by splitting under axial compression is essentially tension fracture. However, from a macroscopic viewpoint, there is no tensile stress in a specimen under axial compression and conventional triaxial compression at low confining pressures. The splitting fracture of rock is essentially caused by tensile strain because of rock's high brittleness and weak capability to withstand tensile strain. For these reasons, the splitting is difficult to describe using the macroscopic stress field, or more appropriately, the strain field. 


\section{An investigation of failure modes and failure criteria of rock in complex stress states}

3. It has been proved that the way the sample fails (the failure mode) affects the obtained strength of the sample. The controlling parameter is a function of the failure mode. Considering tension fracture, local shear failure, and general shear failure, different parameters that dominate these three failure modes were taken into account, and failure criteria corresponding to these three failure modes were developed and presented to evaluate the failure behaviour of rock in various complex stress states. Furthermore, predictions of the failure criterion were compared with experimental data for sandstone, rock salt, and marble under conventional triaxial compression tests. The comparison indicates that the newly proposed failure criterion offers consistent results for these three rock types in a range of stress triaxiality from uniaxial to triaxial compression.

Understanding the effect of failure mode on the failure criterion allows an in-depth interpretation of experimental results obtained in various stress states. The relationship between failure mode and failure criteria of rock samples in various stress states has been elucidated in this paper, with the aim of inducing researchers in rock mechanics to conduct further investigations and provide a theoretical framework to geotechnical applications.

\section{Acknowledgement}

This work was supported by the National Natural Science Foundation of China (Grant no. 11302167) and the research programme of Shaanxi Provincial Education Department (no. 2013JK0609).

\section{References}

Adelinet, M., Fortin, J., Schubnel, A., and GuÉGuen, Y. 2013. Deformation modes in an Icelandic basalt: From brittle failure to localized deformation bands. Journal of Volcanology and Geothermal Research, vol. 255. pp. 15-25.

Amann, F., KaIser, P., and Button, E.A. 2012. Experimental study of brittle behavior of clay shale in rapid triaxial compression. Rock Mechanics and Rock Engineering, vol. 45. pp. 21-33.

ARoRA, S. and Mishra, B. 2015. Investigation of the failure mode of shale rocks in biaxial and triaxial compression tests. International Journal of Rock Mechanics and Mining Sciences, vol. 79. pp. 109-123.

CAI, M.F. and LIU, D.M. 2009. Study of failure mechanisms of rock under compressive-shear loading using real-time laserholography. International Journal of Rock Mechanics and Mining Sciences, vol. 46. pp. 59-68.

CHAng, C.D. and Haimson, B. 2012. A failure criterion for rocks based on true triaxial testing. Rock Mechanics and Rock Engineering, vol. 45. pp. $1007-1010$

FAкHimi, A. and HeмAмi, B. 2015. Axial splitting of rocks under uniaxial compression. International Journal of Rock Mechanics and Mining Sciences, vol. 79. pp. 124-134.

Haimson, B. 2006. True triaxial stresses and the brittle fracture of rock. Pure and Applied Geophysics, vol. 163. pp. 1101-1130.

Kittitep, F. and Decho, P. 2012. Effects of cyclic loading on mechanical properties of Maha Sarakham salt. Engineering Geology, vol. 112. pp. 43-52.

LI, Z.H., SHI, J.P., and TANG, A.M. 2014. Investigation on fracture mechanisms of metals under various stress states. Acta Mechanica, vol. 225 pp. 1867-1881.

LIN, P., Wong, R. H.C., and TANG, C.A. 2015. Experimental study of coalescence mechanisms and failure under uniaxial compression of granite containing multiple holes. International Journal of Rock Mechanics and Mining Sciences, vol. 77. pp. 313-327.

Loaiza, S., Fortin, J., Schubnel, A., Gueguen, Y., Vinciguerra, S., and Moreira, M. 2012. Mechanical behavior and localized failure modes in a porous basalt from the Azores. Geophysical Research Letters, vol. 39. pp. L19304.
Melkoumian, N.S., Priest, D., and Hunt, S.P. 2009. Further development of the three-dimensional Hoek-Brown yield criterion. Rock Mechanics and Rock Engineering, vol. 42. pp. 835-847.

PATERSON, M.S. 2005. Experimental Rock Deformation in the Brittle Field. Springer-Verlag, Berlin, Heidelberg. pp. 132-135.

Salvador, S., Rafael, J., and AleXANDRA, R. 2013. Numerical simulation of the influence of small-scale defects on the true-triaxial strength of rock samples. Computers and Geotechnics, vol. 53. pp. 142-156.

Su, C.D. and Fu, Y.S. 2014. Experimental study of triaxial compression deformation and strength characteristics of sandstone. Chinese Journal of Rock Mechanics and Engineering, vol. 33. pp. 3164-3169.

SzWEDZICKI, T. 2007. A hypothesis on modes of failure of rock samples tested in uniaxial compression. Rock Mechanics and Rock Engineering, vol. 40. pp. 97-104.

TAnapol, S., Chaowarin, W., and KitTitep, F. 2013. True-triaxial compressive strength of Maha Sarakham salt. International Journal of Rock Mechanics and Mining Sciences, vol. 61. pp. 256-265.

TANG, C.A. and Hudson, J.A. 2010. Rock failure mechanisms: explained and illustrated. Taylor and Francis, London. pp. 231-239.

TARAsov, B. and Potvin, Y. 2013. Universal criteria for rock brittleness estimation under triaxial compression. International Journal of Rock Mechanics and Mining Sciences, vol. 59. pp. 57-69.

TiEn, Y.M., Kuo, M.C., and JuANG C.H. 2006. An experimental investigation of the failure mechanism of simulated transversely isotropic rocks. International Journal of Rock Mechanics and Mining Sciences, vol.43. pp. 1163-1181.

TiwARI, R.P. and RAo, K.S. 2004. Physical modeling of a rock mass under a true triaxial stress state. International Journal of Rock Mechanics and Mining Sciences, vol. 41. pp. 1-6.

TIWARI, R.P. and RAo, K.S. 2007. Response of an anisotropic rock mass under polyaxial stress state. Journal of Materials in Civil Engineering, vol. 19. pp. 393-403.

WANG, D., Liu, C.W., WANG, D., LI, X.D., and Xu, Y.H. 2012. Research on the tension-shear deformation and failure criterion of rock under complex stress. Journal of Sichuan University (Engineering Science Edition), vol. 44. pp. 31-35.

Wong, T.F. and BAUD, P. 2012. The brittle-ductile transition in porous rock: A review. Journal of Structural Geology, vol. 44. pp. 25-53.

XIE, H.P. and CHEN, Z.H. 2004. Rock Mechanics. Science Press, Beijing. pp. 129-135.

XIE, H.P., LIU, J.F., Ju, Y., LI, J., and XIE, L.Z. 2011. Fractal property of spatial distribution of acoustic emissions during the failure process of bedded rock salt. International Journal of Rock Mechanics and Mining Sciences, vol. 48. pp. 1344-1351.

XIE, N., ZHU, Q.Z., SHAo, J.F., and Xu, L.H. 2012. Micromechanical analysis of damage in saturated quasi brittle materials. International Journal of Solids and Structures, vol. 49. pp. 919-928.

YANG, S.Q., JiAnG, Y.Z., Xu, W.Y., and CHEN, X.Q. 2008. Experimental investigation on strength and failure behavior of pre-cracked marble under conventional triaxial compression. International Journal of Solids and Structures, vol. 45. pp. 4796-4815.

YANG, S.Q., JING, H.W., and WANG, S.Y. 2012. Experimental investigation on the strength, deformability, failure behavior and acoustic emission locations of red sandstone under triaxial compression. Rock Mechanics and Rock Engineering, vol. 45. pp. 583-606.

YANG, S.Q., Su, C.D., and Xu, W.Y. 2005. Experimental investigation on strength and deformation properties of marble under conventional triaxial compression. Chinese Journal of Rock and Soil Mechanics, vol. 26. pp. 475-478.

You, M.Q. 2009. True-triaxial strength criteria for rock. International Journal of Rock Mechanics and Mining Sciences, vol. 46. pp. 115-127.

Zhigalkin, V.M., Semenov, V.N., Usol'tseva, O.M., Tsoi, P.A., Asanov, V.A., Baryakh, A.A., Pankov, I.L., Toksarov, V.N., and Evseev, A.V. 2008. Deformation of quasi-plastic salt rocks under different conditions of loading. Report II: regularities of salt rock deformation under triaxial compression. Journal of Mining Science, vol. 44. pp. 15-23.

ZHoNG, J.H., Liu, S.X., and MA, Y.S. 2015. Macro-fracture mode and microfracture mechanism of shale. Petroleum Exploration and Development, vol. 42. pp. $269-276$

ZHou, Y. and LiN, J.S. 2013. On the critical failure mode transition depth for rock cutting. International Journal of Rock Mechanics and Mining Sciences, vol. 62. pp. 131-137.

ZHоu, Y. and LiN, J.S. 2014. Modeling the ductile-brittle failure mode transition in rock cutting. Engineering Fracture Mechanics, vol. 127. pp. 135-147. 